Historic, Archive Document

Do not assume content reflects current scientific knowledge, policies, or practices. 


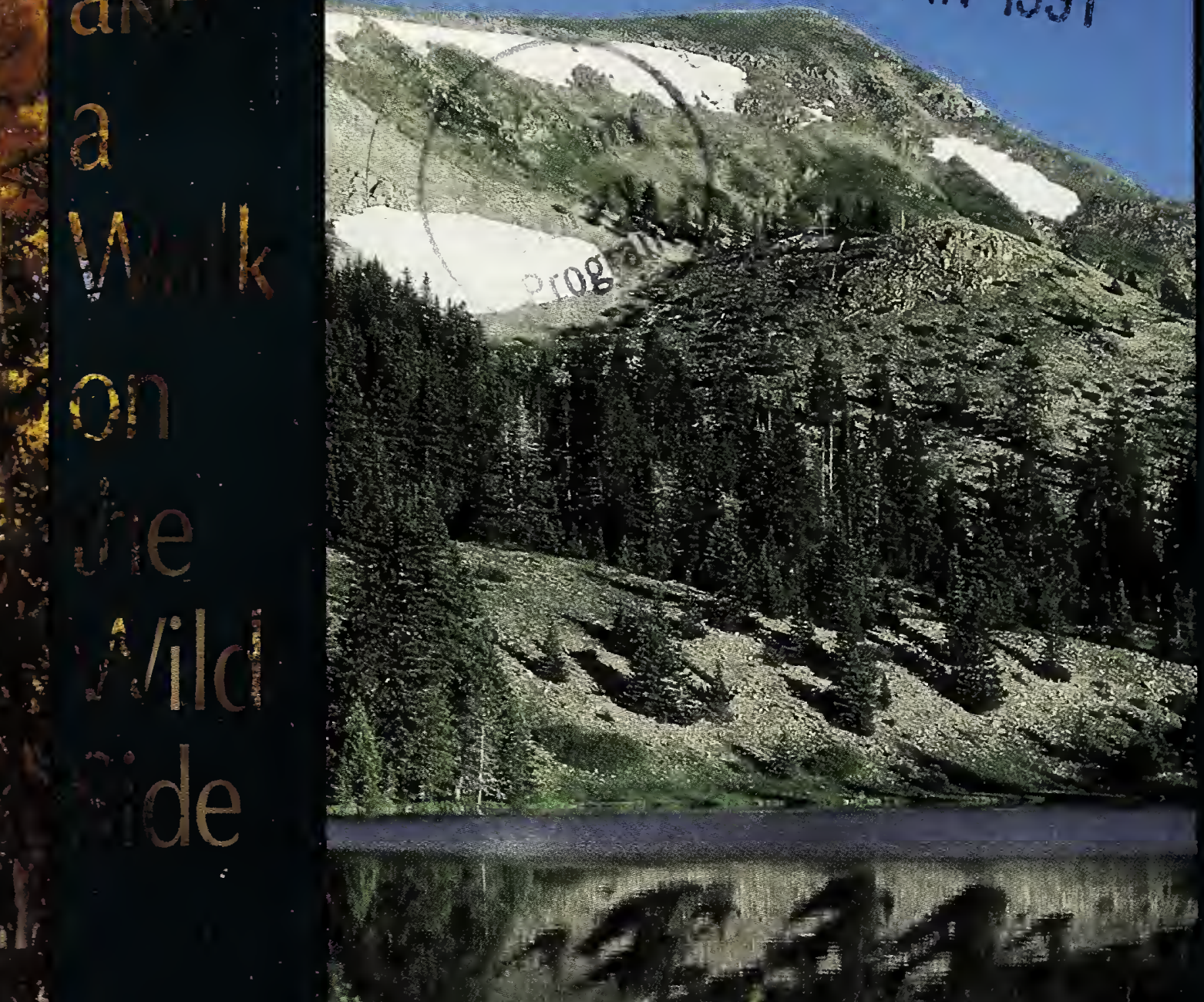

3

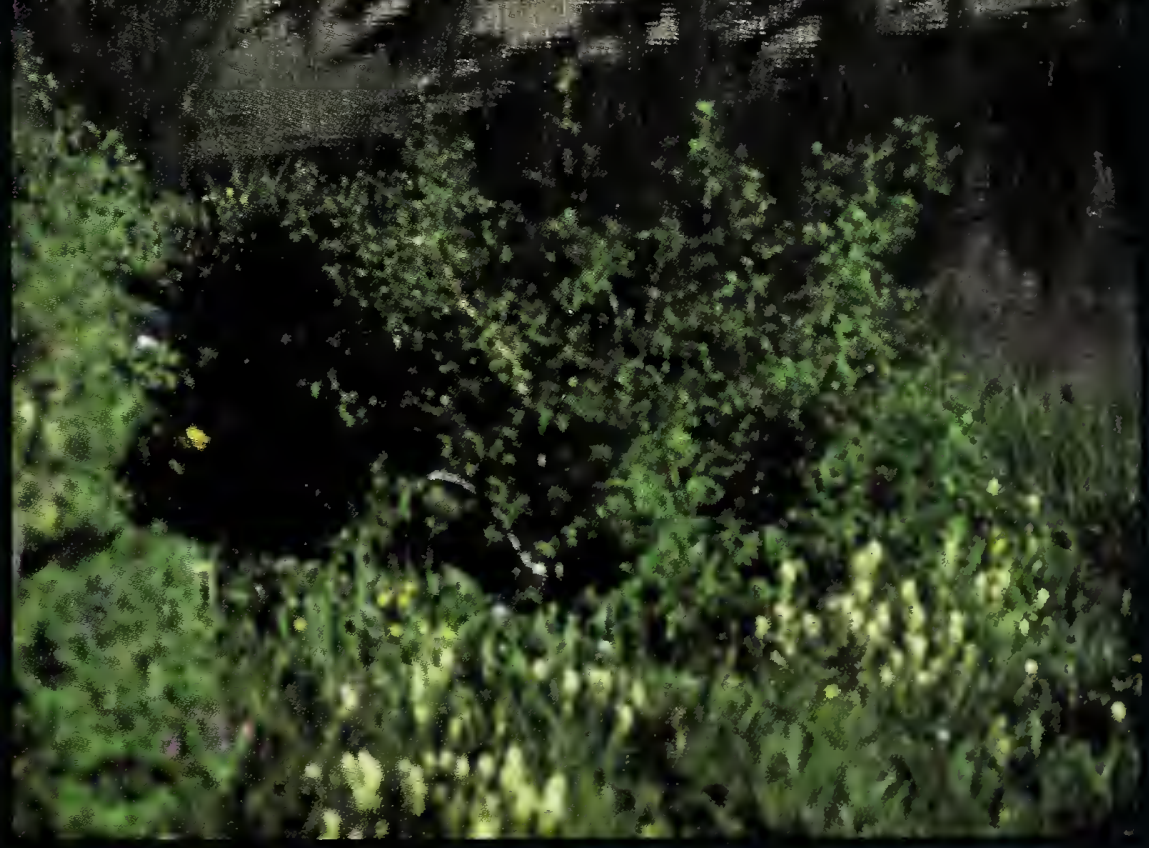

United States

Department of Agriculture
PREPARED BY

Forest

Service
Southwestern Region 


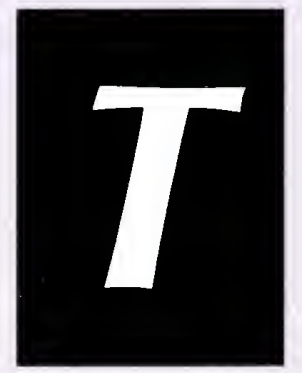

his brochure describes programs that invite

public participation in the enhancement and management of fish and wildlife habitats on National Forest Lands in New Mexico, Arizona, and Oklahoma. The Forest Service has initiated programs to encourage public participation in a variety of emphasis areas including fisheries, endangered species, and other wildlife.
The RISE TO THE

FUTURE program includes cooperation from groups such as the Sport Fishing Institute, Trout Unlimited, the Fish America Foundation, and the angling public. This program emphasizes public education, enhanced fishing opportunities, and participation in fisheries habitat management on National Forest lands.

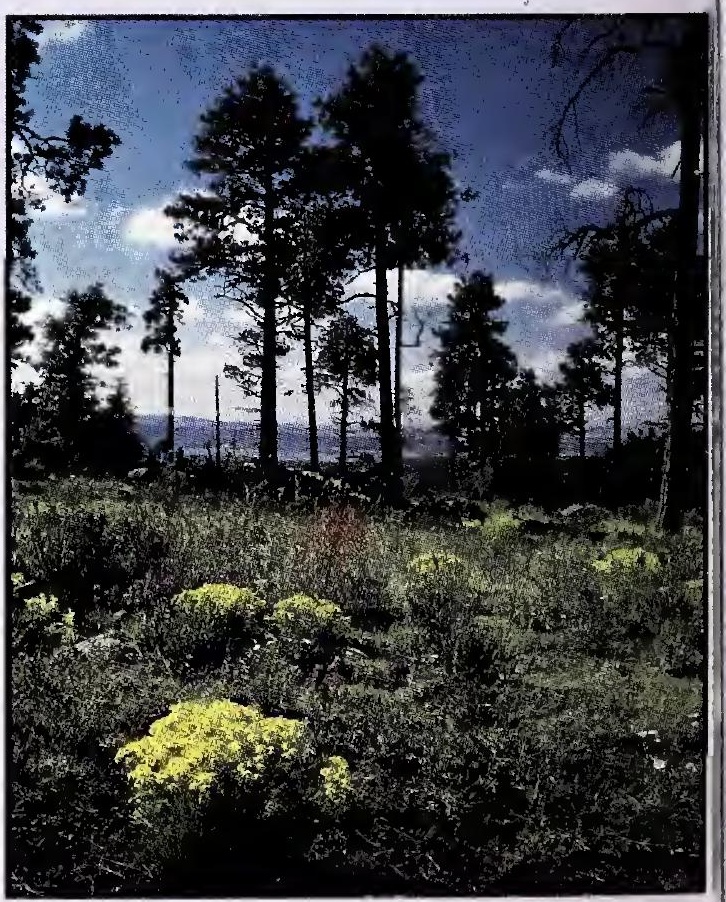


EVERY SPECIES COUNTS is a newly conceived emphasis encouraging public involvement in managing habitats for a variety of threatened, endangered and sensitive fish, wildlife and plants.
'The GET WILD! program attracts a broad spectrum of public participation in projects benefiting various game and nongame wildlife. Although established with the help of "Principal Cooperators," the ten "GET WILD!" programs invite everyone to share in project ideas, costs, materials, or labor.

Choose an area of interest and take part in the management of wildlife and wildlands of National Forest lands in New
OEPT. OF AGRICULTUPE US. OEPT OF AGRICULUURE
MATONALAGRICULTURALLBRARYM Mexico, Arizona and
Oklahoma!

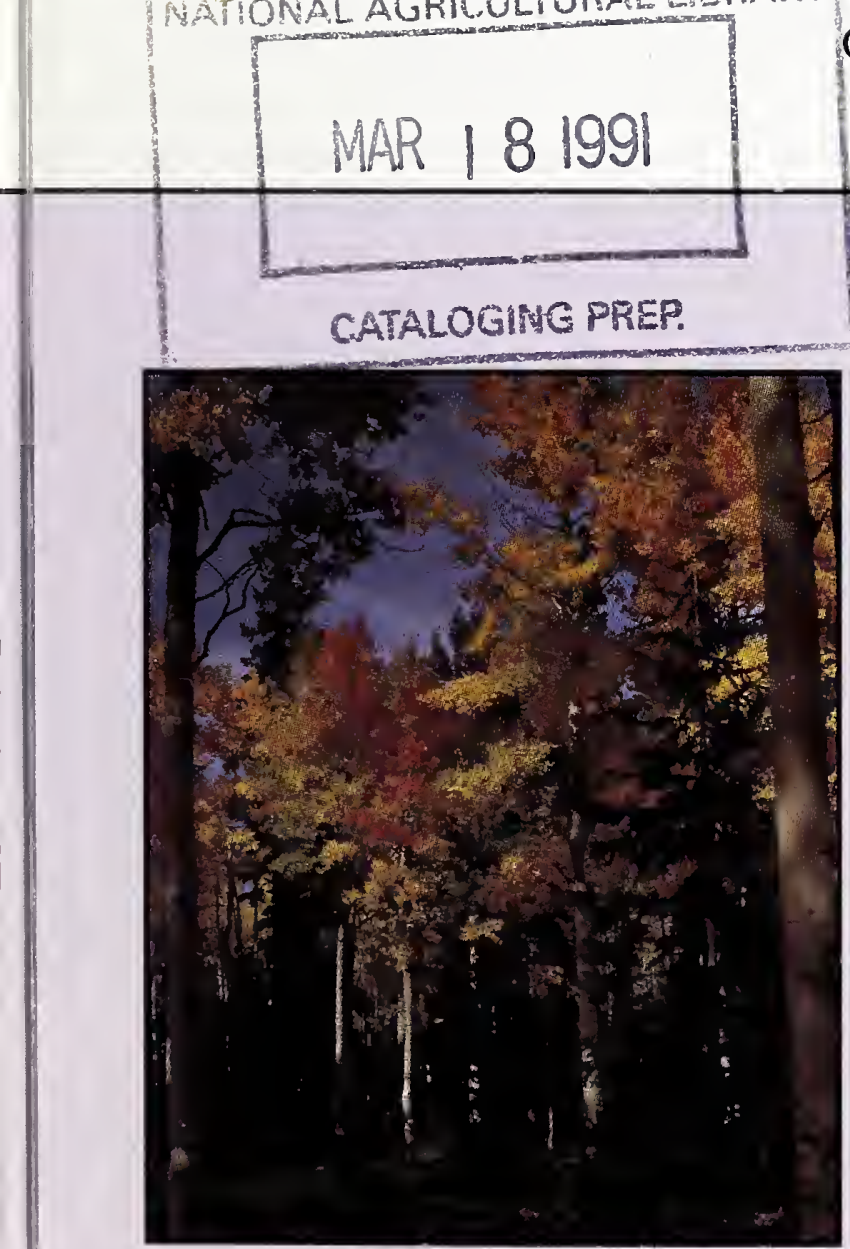

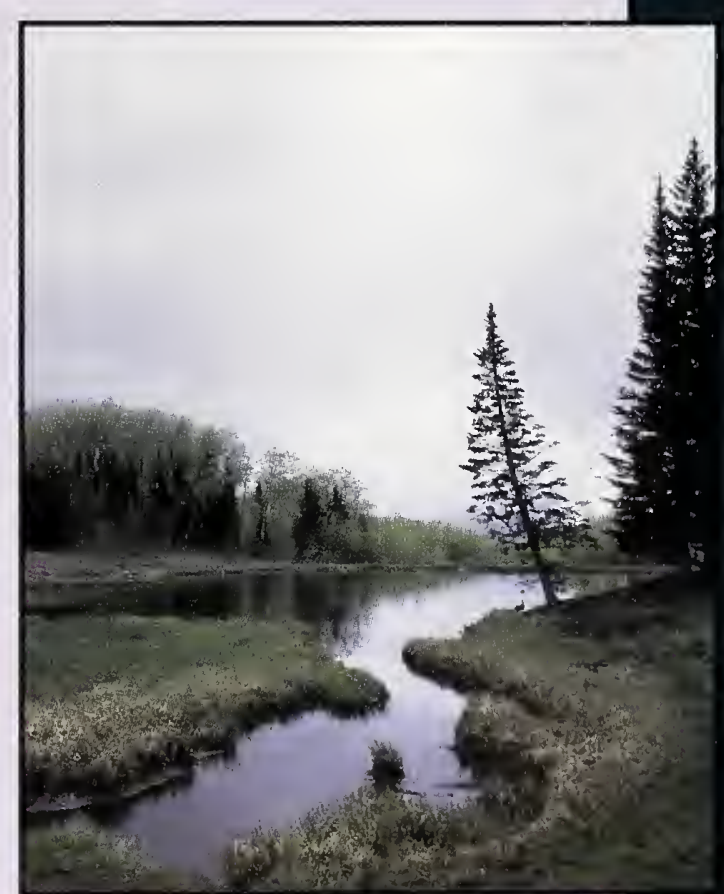





\section{Cet Wild!}

ANIMALINN romoting the value of dead and dying trees as wildlife
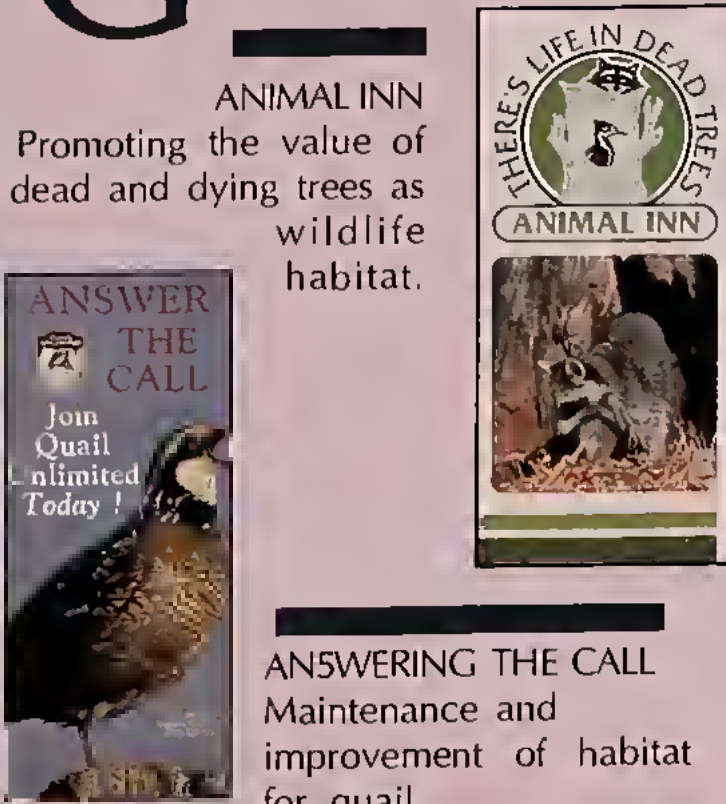

ANSWERING THE CALL Maintenance and improvement of habitat for quail.

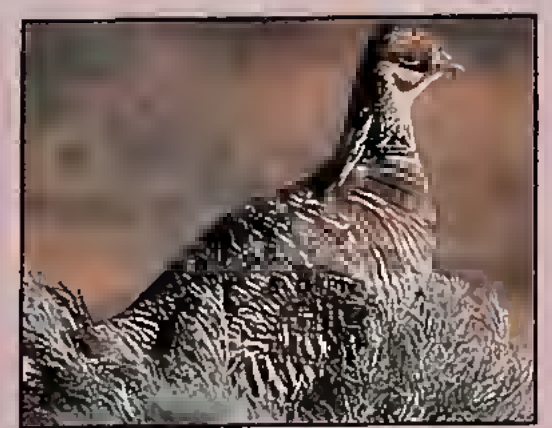

EYE5ON

WILDLIFE

Promotion of non-

consumptive recreational and

educational opportunitie such as bird watching, nature study and photography.

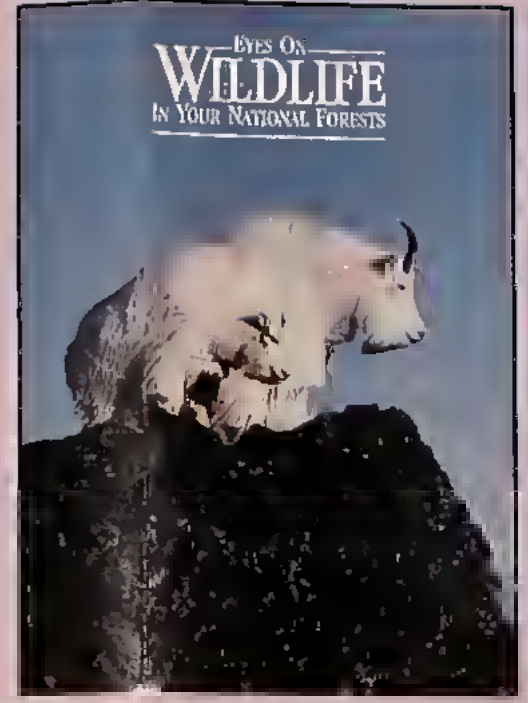

DANCER5 IN THE FORE5T Restoration and

improvement of habitat for woodcock,

sharp-tailed grouse, blue

grouse, sage grouse, prairie chicken, and associated species.

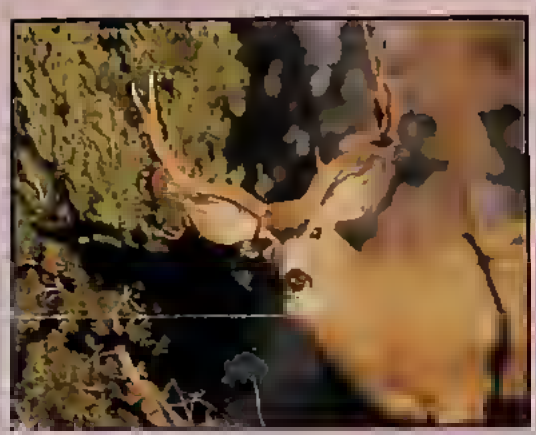

A MILLION BUCK5

Habitat management and enhancement to benefit native deer populations.

ELKCOUNTRY Expansion and improvement of elk habitat on

National Forest Lands.

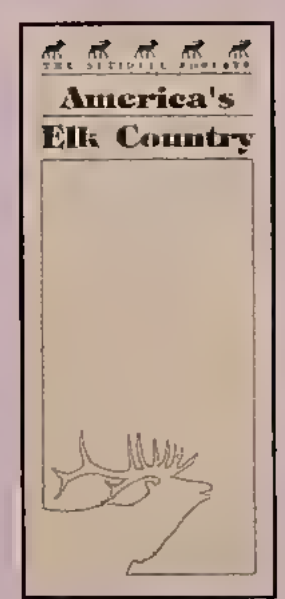

\section{National Forests} and Grasslands Southwestern Region
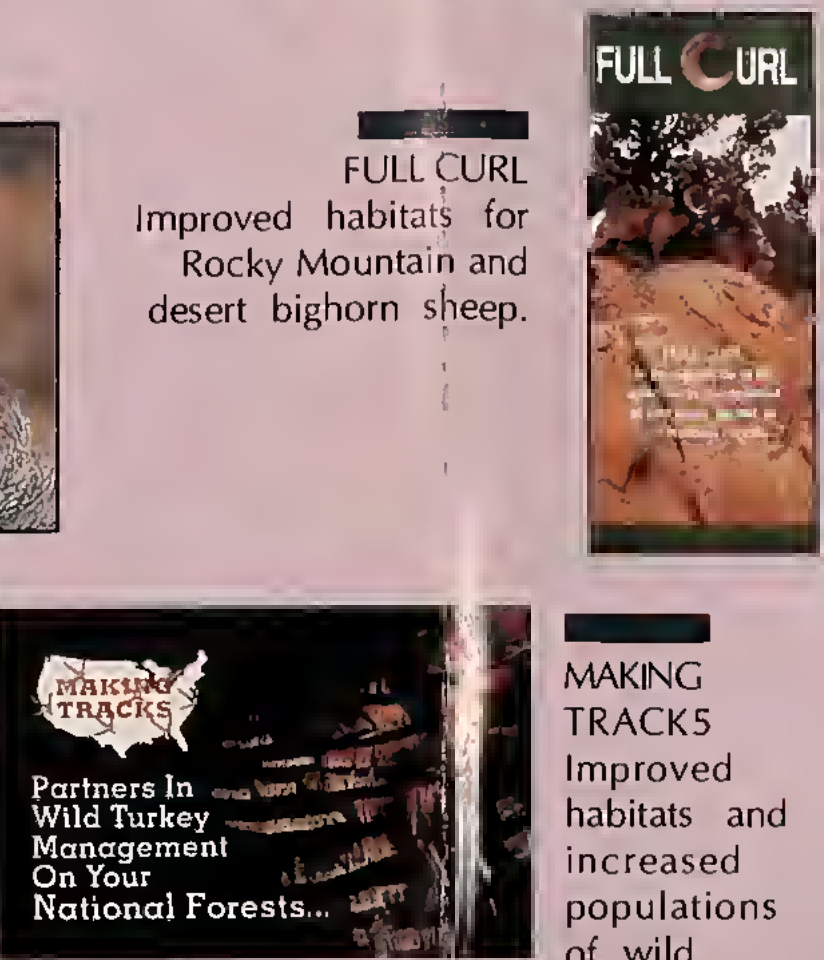
Improved habitats for Rocky Mountain and desert bighorn sheep. Enhanced halji its and increased populations of waterfowl in coordination $v$ i th the North Ams can Waterfowl Management

MAKING TRACK 5 Improved habitats and increased populations of wild turkey.
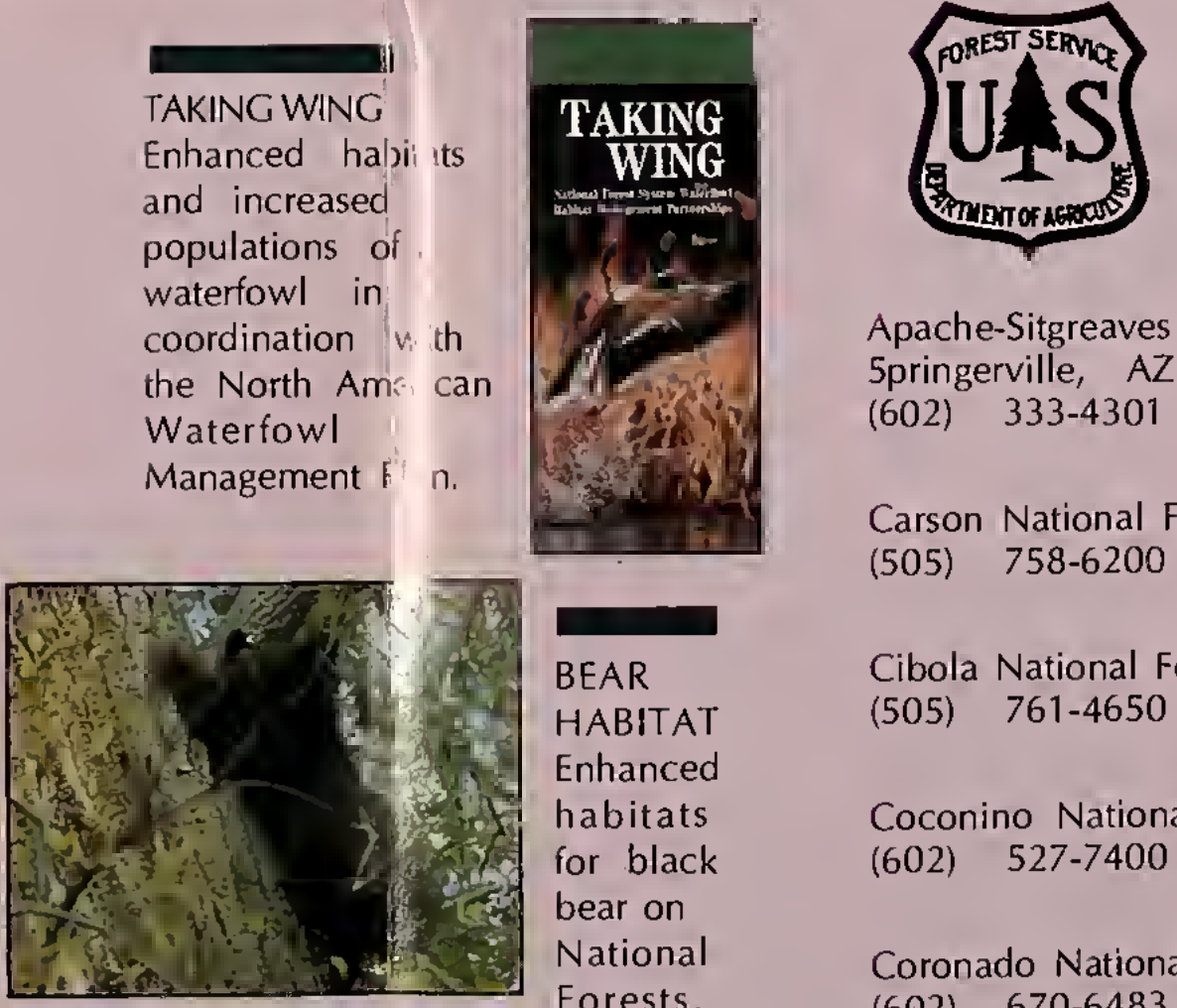

Region 3

Apache-Sitgreaves National Forest 5pringerville, $A Z$ (602) 333-4301

Carson National Forest - Taos, NM (505) 758-6200

Cibola National Forest - Albuquerque, NM (505) 761-4650

Coconino National Forest - Flagstaff, AZ (602) $\quad 527-7400$

Coronado National Forest - Tucson, AZ (602) 670-6483

Gila National Forest - Silver City, NM (505) 388-8201

Kaibab National Forest - Williams, AZ (602) 635-2681

Lincoln National Forest - Alamogordo, NM (505) $\quad 437-6030$

Prescott National Forest - Prescott, AZ (602) $445-1762$

5anta Fe National Forest - Santa Fe, NM (505) $988-6940$

Tonto National Forest - Phoenix, AZ (602) 225-5200 


\section{PHOTO CREDITS}

\section{USDA Forest}

Service and

\section{Front Cover} Hart Lake

Reggie Fletcher

Dancers in the Forest

Rick Wadleigh

Bear Habitat \&

A Million Bucks New Mexico

Department of Game \& Fish 